\title{
Proceedings of the Second Circumpolar Symposium on Remote Sensing of Arctic Environments, Troms $\emptyset$, 4-6 May, 1992
}

\section{Preface}

Remote sensing of polar environments has received increased attention and interest in the last years. The role of the Arctic and the Antarctic in the global circulation system of air and water masses, the sensitive and fragile ecosystems that meet serious threats from pollution and other human impacts, and the huge amount of information about the past changing climates stored in the vast ice sheets and glaciers call for international management and monitoring programs.

Remote sensing from satellites is the only realistic way to collect regular information of the environments from the devastated, mostly unpopulated and hostile, areas around the poles. Today's satellites with polar orbits and tomorrow's polar platforms increase the importance of satellite remote sensing of these parts of the earth. New technology makes it possible to assess the polar regions even through the polar nights.

The Second Circumpolar Symposium on Remote Sensing of Arctic Environments held in Tromsø in May 1992 focused on remote sensing applications in the Arctic and Antarctic, with special emphasis on environmental monitoring and resource mapping. It followed the first and successful symposium held in Yellowknife, Canada, in 1990. Thorbjørn Berntsen, the Norwegian Minister of the Environment, opened the symposium in Tromsø where more than 110 scientists from the United States, Canada, Great Britain, Italy, Estonia, Russia, Switzerland, France, Denmark, Sweden, Finland and Norway attended. The symposium was organized by the University of Troms $\emptyset$, Troms $\emptyset$ Satellite Station, Akvaplan-niva A/S and the Foundation of Applied Research at the University of Troms $\emptyset$ with financial support from the Norwegian Polar Institute, the County of Troms, the Ministry of the Environment and the Ministry of Education and Research.

This special issue of Polar Research, with selected papers from the symposium in Troms $\emptyset$, has become possible in cooperation with the Norwegian Polar Institute. We are grateful to Mary Berge for her work with the manuscripts, to the referees and to the authors. Without their help, this issue would not have materialized. Grateful thanks are extended to the referees and the authors who contributed to this publication and to the speakers and the other participants who made the symposium an accomplishment.

Finally, we wish to thank Director Frits Jensen of the Roald Amundsen Centre for Arctic Research at the University of Troms $\emptyset$, and the secretary, Lillian Jørgensen, who were responsible for the makeup of the supporting staff and the administration of the symposium.

\section{April 1994}

Sigmund Spjelkavik

University of Troms $\emptyset$ 